\title{
Article \\ Agglomeration and Spatial Spillover Effects of Regional Economic Growth in China
}

\author{
Feng $\mathrm{Li}^{1}$ and Guangdong $\mathrm{Li}^{2, *}$ \\ 1 School of Finance, Shanghai Lixin University of Accounting and Finance, Shanghai 201209, China; \\ 20170087@lixin.edu.cn \\ 2 Key Laboratory of Regional Sustainable Development Modeling, Institute of Geographic Sciences and \\ Natural Resources Research (IGSNRR), Chinese Academy of Sciences (CAS), 11A Datun Road, \\ Chaoyang District, Beijing 100101, China \\ * Correspondence: ligd@igsnrr.ac.cn
}

Received: 5 November 2018; Accepted: 7 December 2018; Published: 10 December 2018

\begin{abstract}
As the processes of globalization and localization deepen, spatial externalities of economic growth are becoming increasingly apparent. The agglomeration mechanisms and spillover effects of China's regional economic growth are also gradually gaining attention. Nevertheless, there is a continuing lack of research at the prefecture and county levels. As a result, building on the foundations of new economic geography and centered on the concept of market potential, this paper used spatial econometrics and panel data from Chinese counties to calculate inequality in the economic growth of counties at the prefecture level for the period 1992-2013. It also investigated the agglomeration versus economic inequality trade-off as well as quantitatively measuring spatial spillover effects at the county and prefecture level in China. The results showed that economic agglomeration, represented by market potential, had a significant influence on economic growth at the prefecture level in China. In addition, economic agglomeration exacerbated regional economic inequality, but economic inequality within a controllable range was found to have a positive influence on economic growth. Thus, there is a trade-off between economic growth and economic agglomeration. Economic growth at the prefecture level in China is not yet free of the effects of basic factors of production, and direct spillover effects, represented by market potential, have the most significant and strongest positive influence on economic growth. Moreover, it was found that the economic growth of prefectures was inseparable from the random impacts of surrounding prefectures and that it was also affected by indirect spatial spillover effects. On the whole, the rational use of the benefits of regional economic agglomeration and spillover effects, the gradual removal of market barriers, and the transformation of the development of prefecture-level economic growth will be the keys to prefecture-level economic development in the future.
\end{abstract}

Keywords: market potential; economic agglomeration; new economic geography; spatial spillover effects; county economy; prefecture-scale; China

\section{Introduction}

Since the policy of reform and opening-up was first introduced in 1978, China's economic development has been nothing short of extraordinary. Between 1979 and 2016, China had one of the fastest growing economies in the world, with an average annual growth rate of $9.6 \%$. In 2010, China's total economic output surpassed Japan, making it the world's second largest economy behind the United States [1]. The rapid development and spatial agglomeration of regional economies (production complexes in the geographical sense) should not be overlooked as important factors in China's rapid economic development [2]. Traditional theories of development economics hold that 
the process of economic growth and the dynamics of spatial agglomeration are closely related [3,4]. China's experience of rapid economic development over the past 40 years has affirmed the validity of using regional spatial agglomerations to achieve economic growth. However, although these agglomerations contribute to economic growth, regional disparities in economic development caused by them gradually become more apparent. The trade-off between economic growth and regional inequality has become a problem that policymakers need to consider carefully [5]. On the one hand, regional development policies that encourage specific localities may promote regional agglomerations of economic behavior, leading to unbalanced regional economic development. On the other hand, unbalanced regional economic development may become a source of regional economic growth as a result of technical and knowledge spillovers. For example, at the beginning of the reform and opening-up policy, southeastern coastal areas of China were at the forefront of national economic development thanks to favorable State policies. This led to unbalanced regional development, but it also led to spillovers that positively affected the development of surrounding areas. Nevertheless, if capital is scarce, greater regional inequality will not produce economic efficiency, as the relationship between regional inequality and economic efficiency is not monotonic [5].

\section{Literature Review}

In recent years, the topics of regional economic agglomeration and spatial spillover effects have gradually attracted the attention of international scholars. Scholars generally believe that regional economic agglomeration promotes economic growth. However, few studies have looked at regional economic agglomeration and economic growth in China. The findings of C. Cindy Fan and Allen Scott's study are relatively representative [6]. They found a positive correlation between economic agglomeration and economic growth using industrial agglomeration surveys. He et al., meanwhile, investigated the geographical agglomeration of China's manufacturing industry and found that economic agglomeration has a positive influence on economic growth and knowledge spillovers [7].

Spatial spillover effects are an externality of the agglomeration of economic activities. The market-based reforms introduced by reform and opening-up have, to a certain degree, eliminated the market fragmentation that existed in the era of the planned economy. They have also accelerated flows of factors of production and products of labor, improved resource allocation and market accessibility, and thus promoted knowledge, industrial, and economic spillovers between regions [8]. The policy of opening-up, meanwhile, introduced foreign advanced technology and management expertise to China, which accelerated spillover effects. Foreign direct investment is a core driver of spillover effects, and it played a major role in promoting economic growth in China's coastal areas in the early stage of reform. The particular path of economic development taken by China makes it a good laboratory for studying regional economic spillovers. As a result, the spillover effects of China's regional economies have attracted the attention of numerous scholars.

Ying [9], for example, believes that there are clear spillovers between core and peripheral areas in China. Brun et al. [10] divided China into coastal and inland areas and used dummy variables for eastern, central, and western regions of China to discover that spillover effects from coastal to inland areas do exist. Groeneweld, Guoping, et al. [11] used a VAR (vector autoregression) model and impulse response functions to simulate spillover effects between China's eastern, central, and western regions, discovering that spillover effects exist from the eastern region to the central and western regions and from the central region to the western region. Groeneweld, Lee, et al. [12] conducted a study looking at China's six major economic regions and discovered that different spillover effects exist between different regions. Groeneweld, Chen, et al. [13] found that spillovers from policy shock are greater in China's eastern region than in the central and western regions, and greater in the central region than in the western region. Based on a new economic geography model signaling the effects of market potential on regional economic development, Pan [8] found spillovers between China's provincial economic growth and found that spatial spillovers play an important role in China's regional economic development. Finally, Tian et al. [14] utilized spatial econometrics to examine spatial externalities in 
the economic growth of 313 cities in China and discovered significant positive spatial dependence since 1991.

From a review of relevant literature, it is easy enough to find that the vast majority of studies on regional economic agglomeration focus on the national and provincial levels. Studies on spatial spillover effects, meanwhile, tend to focus on spillovers between coastal and inland areas or between China's eastern, central, and western regions. Occasionally, scholars have looked at interactions between China's six major economic regions [12], but studies on spillovers at the provincial level [8] and prefecture-level spatial externalities [14] are rare. For a country such as China, with more than 2000 counties and 330 prefectures, it is more likely that spatial spillover effects will be at or below the prefecture level. As local protectionism is gradually contained and market segmentation gradually eliminated, prefecture- and county-level flows of factors of production may accelerate, and economic links and interactions may deepen. As a result, regardless of whether one is studying regional economic agglomeration or measuring regional economic spillover effects, it is better to consider smaller scales. Looking at the county- and prefecture-level economies may make it easier to understand economic agglomeration and spillover effects in the whole of China.

The existence of spatial autocorrelation and heterogeneity may have an impact on traditional regression analysis results, however. Some scholars have pointed out that the traditional method of ordinary least squares (OLS) regression is biased when analyzing spatially significant data [15-17]. Because of this, spatial econometric models whose core objective is to control spatial effects have been widely used, but few studies have used spatial econometrics in applied research on regional economic agglomerations and spillover effects. Pan's [8] use of a spatial error model (SEM) to examine the economic links and spillover effects between 31 Chinese provinces and Tian et al.'s [14] use of the spatial Durbin model to test the spatial externalities of economic growth of municipal units are fairly representative examples.

With the above analysis in mind, and based on the theory of new economic geography and focusing on China's 2286 stable counties, this paper first calculated economic growth inequality between counties within each prefecture-level administrative unit and then used a spatial econometric model to calculate prefecture-level economic growth agglomeration and spatial spillover effects.

\section{Materials and Methods}

\subsection{Theoretical Model}

In recent years, new economic geography has explored the mechanisms of polarization and inequality in regional economic growth from the perspective of the cumulative cyclical effects of the relationship and interactions between supply and demand, referred to as the "spatial externalities of large geographical agglomerations" [18]. Using spatial distance as a weight, the potential demand for a region's products and services can be determined by totaling up the GDP of surrounding areas, and market potential can be utilized to study the impact on regional wage levels. Some scholars have extended this concept and applied it to research on regional economic growth. For example, Crozet and Koenig [5] use panel data from European countries to find that market potential has a significant positive influence on GDP per capita. It is important to note that the differences between developed and developing countries are likely to be significant and may have been caused by differential patterns of economic development. For example, China implemented a growth pattern of developing country with high depletion, high devotion, high pollution, and high consumption, which differed from the advanced growth pattern of developed countries. However, further investigation may be needed to confirm this difference. 
Although the theoretical model's inference process is different, spatial externalities can be expressed by the wage equation in new economic geography. The simplified model is as follows:

$$
w_{r}=\left(\sum_{s=1}^{R} Y_{s} e^{-\tau(\sigma-1) d_{s r}} P_{s}^{\sigma-1}\right)^{\frac{1}{\sigma}},
$$

where $w_{r}$ is the price of labor of region $\mathrm{r} ; Y_{S}$ and $P_{S}$ represent the total consumption expenditure and price index of region $s ; e^{-\tau(\sigma-1) d_{s r}}$ is the iceberg trade cost between regions $r$ and $s$, which is an increasing function of geographical distance $d_{s t}$, and where $\tau$ is the transportation cost per unit of distance; and $\sigma$ is the product's elasticity of substitution. $\sum_{s=1}^{R} Y_{s} e^{-\tau(\sigma-1) d_{s r}} P_{s}^{\sigma-1}$ is market potential in Krugman's sense. Krugman's theory of market potential is more akin to the general path of regional agglomeration development. That is to say, the speed of economic development of a region with a high level of economic development is likely to be faster than other regions and its overall economic output is likely to be greater; therefore, its demand for the products and services of surrounding regions is likely to be higher, which means that it has a relatively strong driving effect on surrounding regions. However, it also means that there will be greater regional inequality. While regional inequality may be beneficial to regional economic development to a certain extent, it may lead to ineffective regional development when a certain threshold is exceeded. If $M P_{r}$ is the market potential of region $r$, and per capita income replaces wages in Equation (1), the following basic equation that simplifies the association between per capita income and the market potential can be derived:

$$
\ln \left(Y_{r}\right)=\gamma \ln \left(M P_{r}\right),
$$

where $Y_{r}$ is the per capita GDP of prefecture $r . G D P_{s t}$ in $M P_{r t}=\sum_{s \neq r} \frac{G D P_{s t}}{d_{r s}}$ is the GDP of region $s$ in year $t$, and $d_{r s}$ is the Euclidean distance between prefectures.

Giving further consideration to spatial inequality at the prefecture level, the relationship between market potential and spatial inequality can be expressed as shown in Equation (3):

$$
\ln \left(Y_{r}\right)=\gamma_{0}+\gamma_{1} \ln \left(M P_{r}\right)+\gamma_{2} \ln \left(\text { Ineq }_{r}\right)
$$

where Ineq $r$ is the spatial inequality of prefecture $r$, with the level of inequality calculated using the Gini coefficient. The Gini coefficient for China's prefectures is calculated based on county data. The equation for calculating it is as follows $[19,20]$ :

$$
\text { Ineq }_{r}=\left(\frac{1}{2 \bar{y}_{\mathrm{u}}}\right) \frac{1}{n(n-1)} \sum_{i}^{n} \sum_{j}^{n}\left|y_{i}-y_{j}\right|
$$

where $y_{i}$ and $y_{j}$ are the GDP per capita of administrative units $i$ and $j ; n$ is the number of administrative units; $\bar{y}_{\mathrm{u}}$ is the average GDP per capita; and Ineq $q_{r}$ is the Gini coefficient value from 0 to 1 . Since county-level data is used to calculate the Gini coefficient for prefecture-level administrative units, $n$ specifically refers to the number of county-level administrative units within each prefecture-level administrative unit.

\subsection{Model Specification}

Based on the above theoretical analysis, GDP per capita replaces the per capita income, and the level of GDP per capita represents the effect other regions have on a region's economic growth. Once the time dimension is introduced, an econometric model that examines the regional economic growth versus regional inequality trade-off can be expressed as follows: 


$$
\ln \left(\frac{Y_{r, t}}{Y_{r, t-1}}\right)=\gamma_{0}+\gamma_{1} \ln \left(\frac{M P_{r, t}}{M P_{r, t-1}}\right)+\gamma_{2} \ln \left(\frac{\text { Ineq }_{r, t}}{\text { Ineq }_{r, t-1}}\right)
$$

A region's GDP per capita growth depends on changes in both regional market entry and regional spatial inequality. Equation (5) represents the spatial agglomeration versus economic growth trade-off, that is, the positive influence that the increasing regional spatial inequality should have on the growth of a region's GDP per capita.

Classical growth theory and new growth theory hold that capital, labor, and human capital are the main driving forces of regional economic growth. In addition, to examine the impact of overseas markets and geographic location on economic growth, we followed the processing method of Pan [8], which uses distance to the nearest seaport and distance to the nearest provincial capital from prefectures as surrogate variables. As such, the specifications of the model for measuring spatial spillover effects are as follows:

$$
\begin{aligned}
\ln \left(\frac{Y_{r, t}}{Y_{r, t-1}}\right)= & \beta_{0}+\beta_{1} \ln \left(\frac{M P_{r, t}}{M P_{r, t-1}}\right)+\beta_{2} \ln \left(\frac{L_{r, t}}{L_{r, t-1}}\right)+\beta_{3} \ln \left(\frac{K_{r, t}}{K_{r, t-1}}\right)+\beta_{4} \ln \left(\frac{H_{r, t}}{H_{r, t-1}}\right) \\
& +\beta_{5} \ln d p_{r}+\beta_{6} \ln d c_{r}+\mu_{r, t}
\end{aligned}
$$

where $r$ is the prefecture, $t$ is the year, $Y_{r, t}$ is the GDP per capita of region $r$ in year $t ; L_{r, t} / L_{r, t-1}$ represents changing labor; $K_{r, t} / K_{r, t-1}$ denotes changing fixed-asset investment; $H_{r, t} / H_{r, t-1}$ signifies changing human capital; $d_{p r}$ represents the distance from each prefecture to the nearest seaport; and $d_{c r}$ represents the distance from each prefecture to the nearest provincial capital. Table 1 shows the descriptive statistics for all key variables in the estimation of Equations (5) and (6), including both measures of regional inequality and market potential.

Table 1. Descriptive statistics of variables (Source: modified by the authors).

\begin{tabular}{ccccc}
\hline Variable & Mean & Std. Dev. & Max & Min \\
\hline $\ln \left(\mathrm{y}_{\mathrm{r}, \mathrm{t}} / \mathrm{y}_{\mathrm{r}, \mathrm{t}-1}\right)$ & 0.1122 & 0.0232 & 0.1925 & 0.0012 \\
$\ln \left(\mathrm{Ineq}_{\mathrm{r}, \mathrm{t}}\right)$ & 0.0548 & 2.9422 & 0.0943 & -0.0041 \\
$\ln \left(\mathrm{MP}_{\mathrm{r}, \mathrm{t}} / \mathrm{MP}_{\mathrm{r}, \mathrm{t}-1}\right)$ & 0.1457 & 2.0812 & 0.5911 & -0.1992 \\
$\ln \left(\mathrm{L}_{\mathrm{r}, \mathrm{t}} / \mathrm{L}_{\mathrm{r}, \mathrm{t}-1}\right)$ & 0.0029 & 0.0734 & 0.0833 & -0.0835 \\
$\ln \left(\mathrm{K}_{\mathrm{r}, \mathrm{t}} / \mathrm{K}_{\mathrm{r}, \mathrm{t}-1}\right)$ & 0.2947 & 1.1776 & 0.5224 & -0.7340 \\
$\ln \left(\mathrm{H}_{\mathrm{r}, \mathrm{t}} / \mathrm{H}_{\mathrm{r}, \mathrm{t}-1}\right)$ & 0.0072 & 0.1784 & 0.1662 & -0.1087 \\
$\ln \left(\mathrm{d}_{\mathrm{pr}}\right)$ & 7.1043 & 1.2795 & 9.6249 & 0.0000 \\
$\ln \left(\mathrm{d}_{\mathrm{cr}}\right)$ & 5.2464 & 0.9376 & 7.9388 & 0.0000 \\
\hline
\end{tabular}

\subsection{Model Estimation}

A large volume of research and analysis has shown that China's regional economic growth has spatial autocorrelations. Using 2013 data on GDP per capita for China's prefectures, analysis using Moran's I shows that a significant spatial autocorrelation also exists for China's prefecture-level economic growth, with a Moran's I value of 0.489 (and a z-score of 38.36). In the previous model specifications, the market potential variable was used to characterize the spatial effect, but the spatial effect is more complicated and may not be fully captured by that variable. Spatial errors can be introduced into the model by other factors, resulting in the model having strong spatial autocorrelation. As such, we attempted to estimate the economic growth agglomeration versus economic growth trade-off of China's prefectures by using a spatial autoregressive model (SAR) and a spatial error model (SEM).

The SAR model can be expressed as follows:

$$
\ln \left(\frac{Y_{r, t}}{Y_{r, t-1}}\right)=\delta \sum_{s=1}^{N} w_{r, s} \ln \left(\frac{Y_{r, t}}{Y_{r, t-1}}\right)+\beta_{1} \ln \left(\frac{M P_{r, t}}{M P_{r, t-1}}\right)+\beta_{2} \ln \left(\frac{\text { Ineq }_{r, t}}{\text { Ineq }_{r, t-1}}\right)+\mu_{r}+\varepsilon_{r, t}
$$


where $\delta$ is the spatial autoregressive coefficient; and $\mu_{r}$ and $\varepsilon_{r, t}$ are special spatial effects and random errors, respectively. $w_{r, s}$ is a $330 \times 330$ row-normalized spatial weight matrix with zero diagonal elements, which define relations of proximity between two prefectures ( $r$ and $s)$. In this paper, we used a binary contiguity spatial weight matrix model to generate a spatial weight matrix.

The SEM model can be expressed as follows:

$$
\ln \left(\frac{Y_{r, t}}{Y_{r, t-1}}\right)=\beta_{1} \ln \left(\frac{M P_{r, t}}{M P_{r, t-1}}\right)+\beta_{2} \ln \left(\frac{\text { Ineq }_{r, t}}{\text { Ineq }_{r, t-1}}\right)+\mu_{r}+\phi_{r, t}, \phi_{r, t}=\rho \sum_{s}^{N} w_{r, s} \phi_{r, t}+\varepsilon_{r, t}
$$

where $\rho$ is the spatial autocorrelation coefficient; and $\mu_{r}$ and $\phi_{r, t}$ are special spatial effects and random errors, respectively.

Referring to the processing method used by Pan [8] when choosing the fixed effect and random effect estimation method, we chose the most commonly used fixed effect. Model estimation was carried out using the maximum likelihood method.

Similar to the model for measuring the economic growth agglomeration versus growth trade-off, the spillover effect of prefecture-level economic growth also has spatial autocorrelations, which may be stronger. As such, spatial econometrics is also used to control spatial autocorrelations. Based on the different estimation methods, Equation (6) can be made into a SAR model (Equation (9)) and a SEM model (Equation (10)):

$$
\begin{aligned}
\ln \left(\frac{Y_{r, t}}{Y_{r, t-1}}\right)= & \delta \sum_{s=1}^{N} w_{r, s} \ln \left(\frac{Y_{r, t}}{Y_{r, t-1}}\right)+\beta_{1} \ln \left(\frac{M P_{r, t}}{M P_{r, t-1}}\right)+\beta_{2} \ln \left(\frac{L_{r, t}}{L_{r, t-1}}\right)+\beta_{3} \ln \left(\frac{K_{r, t}}{K_{r, t-1}}\right) \\
+ & \beta_{4} \ln \left(\frac{H_{r, t}}{H_{r, t-1}}\right)+\beta_{5} \ln d p_{r}+\beta_{6} \ln d c_{r}+\mu_{r}+\varepsilon_{r, t} \\
\ln \left(\frac{Y_{r, t}}{Y_{r, t-1}}\right)= & \beta_{1} \ln \left(\frac{M P_{r, t}}{M P_{r, t-1}}\right)+\beta_{2} \ln \left(\frac{L_{r, t}}{L_{r, t-1}}\right)+\beta_{3} \ln \left(\frac{K_{r, t}}{K_{r, t-1}}\right)+\beta_{4} \ln \left(\frac{H_{r, t}}{H_{r, t-1}}\right) \\
& +\beta_{5} \ln d p_{r}+\beta_{6} \ln d c_{r}+\mu_{r}+\phi_{r, t}, \phi_{r, t}=\rho \sum_{s} w_{r, s} \phi_{r, t}+\varepsilon_{r, t}
\end{aligned}
$$

The specifications for Equations (9) and (10) are the same as in the previous equations.

\subsection{Data Sources}

The calculations in this paper cover eight specific variables: GDP per capita (Y); market potential (MP), calculated using GDP per capita and prefecture distances; regional inequality index (Ineq), calculated based on GDP per capita; workforce level of prefectures (L), based on labor participation rate data; level of investment of prefectures $(K)$, based on per capita fixed-asset investment data; level of human capital of prefectures $(\mathrm{H})$, based on number of students of regular higher education institutions per 10,000 people; distance from the prefecture to the nearest seaport (dp); and distance from the prefecture to the nearest provincial capital (dc). Data on the distance from prefectures to the nearest seaport and provincial capital were obtained using cost distance analysis in ArcGIS 10.2, the basic data being administrative division data. Other data sources include the China Statistical Yearbook for Regional Economy (2000-2014), the China County Statistical Yearbook (2000-2014), and the China City Statistical Yearbook (1993-2014).

\section{Results}

\subsection{Economic Growth Agglomeration versus Growth Trade-Off at the Prefecture Level in China}

Table 2 shows the results of calculations on the economic growth agglomeration versus growth trade-off. The processing software chosen was Matlab2012a, and the spatial econometric model code came from http:/ / www.spatial-econometrics.com/. In Equations (5)-(8), we used the market potential growth rate and regional inequality as the explanatory variables and the GDP per capita growth rate as the explained variable. The research sample consisted of 330 prefectures in China's mainland 
from 1992 to 2013, covering 2286 stable counties. In terms of the estimation model selected, we first used a traditional panel OLS regression analysis for comparison, and then used SAR and SEM for regression analysis. We chose spatial fixed, time-period fixed and spatial and time-period fixed estimation methods. Comparing the regression results, particularly the LM (Lagrange multiplier) test, the robust LM test, and the adjusted $\mathrm{R}^{2}$ and log-likelihood values, it was found that the SEM spatial fixed model was the most suitable model because the LM spatial error and the robust LM spatial error were significantly greater than the LM spatial lag and the robust LM spatial lag, respectively. However, although the model controlled some spatial autocorrelation, some of it was uncontrollable, so the $\rho$-value was still high at 0.642 . The SEM spatial fixed model also indicated that although we described the spillover effect between prefectures by introducing market potential, the market potential could not contain all the factors of spatial spillover. Therefore, those factors that were not introduced in the market potential and had spatial correlation entered the random error term in the model. This result also implied that the economic growth of prefectures in China was also closely related to the random impact of the surrounding prefectural economic growth. The parameter $\rho$, revealing the spatial correlation between regression residuals, was significantly non-zero, indicating that other factors affecting regional economic growth also had a diffusion effect on neighboring regional economic growth, which could be considered as an indirect spatial spillover effect. In short, the spatial spillover effect between prefectures played an important role in the economic development of China.

Table 2. Regression results of economic growth and spatial inequality for China's prefectures (Source: modified by the authors).

\begin{tabular}{|c|c|c|c|c|c|c|c|}
\hline & \multirow[b]{2}{*}{ Pooled OLS } & \multicolumn{3}{|c|}{ SAR } & \multicolumn{3}{|c|}{ SEM } \\
\hline & & $\begin{array}{l}\text { Spatial } \\
\text { Fixed }\end{array}$ & $\begin{array}{l}\text { Time-Period } \\
\text { Fixed }\end{array}$ & $\begin{array}{c}\text { Spatial and } \\
\text { Time-Period } \\
\text { Fixed }\end{array}$ & $\begin{array}{l}\text { Spatial } \\
\text { Fixed }\end{array}$ & $\begin{array}{l}\text { Time- } \\
\text { Period } \\
\text { Fixed }\end{array}$ & $\begin{array}{c}\text { Spatial and } \\
\text { Time-Period } \\
\text { Fixed }\end{array}$ \\
\hline Constant term & $\begin{array}{l}0.0151^{* * *} \\
(61.6648)\end{array}$ & & & & & & \\
\hline $\ln \left(\mathrm{MP}_{\mathrm{r}, \mathrm{t}} / \mathrm{MP}_{\mathrm{r}, \mathrm{t}-1}\right)$ & $\begin{array}{c}0.8609 * * * \\
(1112.7334)\end{array}$ & $\begin{array}{l}0.8473 * * * \\
(920.5675)\end{array}$ & $\begin{array}{l}0.8459 \text { *** } \\
(794.3667)\end{array}$ & $\begin{array}{l}0.8469 * * * \\
(793.2831)\end{array}$ & $\begin{array}{c}0.8476^{* * *} \\
(1134.4835)\end{array}$ & $\begin{array}{c}0.8627^{* * *} \\
(1012.2315)\end{array}$ & $\begin{array}{c}0.8632 * * * \\
(1012.0387)\end{array}$ \\
\hline $\ln \left(\right.$ Ineq $_{r, t} /$ Ineq $\left._{r, t-1}\right)$ & $\begin{array}{l}0.0369^{* * *} \\
(337.7134)\end{array}$ & $\begin{array}{l}0.0364^{* * *} \\
(333.1302)\end{array}$ & $\begin{array}{l}0.0358^{* * *} \\
(291.6542)\end{array}$ & $\begin{array}{l}0.0357^{* * *} \\
(288.1932)\end{array}$ & $\begin{array}{l}0.0381^{* * *} \\
(426.9592)\end{array}$ & $\begin{array}{l}0.0374^{* * *} \\
(343.2075)\end{array}$ & $\begin{array}{l}0.0373^{* * *} \\
(339.8677)\end{array}$ \\
\hline$\delta$ & & $\begin{array}{c}0.0370 * * * \\
(28.1991)\end{array}$ & $\begin{array}{c}0.0580 * * * \\
(31.1981)\end{array}$ & $\begin{array}{c}0.0570 * * * \\
(30.5796)\end{array}$ & & & \\
\hline$\rho$ & & & & & $\begin{array}{l}0.6420 * * * \\
(123.7623)\end{array}$ & $\begin{array}{c}0.5200 \\
(0.0000)\end{array}$ & $\begin{array}{c}0.5200 \\
(0.0000)\end{array}$ \\
\hline Adjusted $\mathrm{R}^{2}$ & 0.9827 & 0.9822 & 0.9787 & 0.9773 & 0.9880 & 0.9822 & 0.9809 \\
\hline$\sigma^{2}$ & 0.0014 & 0.0014 & 0.0017 & 0.0017 & 0.0009 & 0.0015 & 0.0014 \\
\hline LM spatial lag & $927.61 * * *$ & $28.61^{* * *}$ & $856.36^{* * *}$ & $868.34^{* * *}$ & $958.43^{* * *}$ & $965.45^{* * *}$ & $953.23 * * *$ \\
\hline LM spatial error & $16,324.70^{* * *}$ & $17,324.70^{* * *}$ & $17,435.46^{* * *}$ & $17,457.15^{* * *}$ & $18,123.53^{* * *}$ & $18,012.09^{* * *}$ & $18,012.13^{* * *}$ \\
\hline Robust LM spatial lag & $176.43^{* * *}$ & $179.10^{* * *}$ & $179.34^{* * *}$ & $178.64^{* * *}$ & $179.41 * * *$ & $175.34 * * *$ & $178.84^{* * *}$ \\
\hline Robust LM spatial error & $15,573.52 * * *$ & $16,245.96^{* * *}$ & $16,315.42 * * *$ & $16,324.35 * * *$ & $16,534.51 * * *$ & $16,235.13 * * *$ & $16,341.34^{* * *}$ \\
\hline Log-likelihood & 55,262 & 55,976 & 51,167 & 51,382 & 60,605 & 53,997 & 54,193 \\
\hline Observation & 330 & 330 & 330 & 330 & 330 & 330 & 330 \\
\hline
\end{tabular}

Note: $t$-test values are provided in parentheses; ${ }^{* * *}$ indicates significant at the level of $1 \%$.

Overall, the specific influence coefficient of market potential on GDP per capita growth rate is around 0.85 and is significant at the level of $1 \%$. This shows that market potential has a strong and significant positive influence on prefecture-level economic growth. In theory, if market potential increases by $0.85 \%$, it can promote prefecture-level GDP per capita growth by $1 \%$. Moreover, it means that the market potential of surrounding areas is an influencing factor in the economic growth of prefectures in China. Economic agglomeration promotes economic growth of prefectures to a certain extent. This result is in line with the expectations of the new economic geography, that is, a region has good opportunities to enter other large-scale markets, and the externalities generated by the correlation effects will bring higher growth levels to this region [5]. 
In addition, Table 2 shows that increased regional inequality has a significant positive influence on regional economic growth. Using the Gini coefficient as the explanatory variable, the research results showed that the influence coefficient was around 0.036 . It implied that a $10 \%$ increase in the Gini coefficient of prefectures would lead to a $0.36 \%$ increase in regional GDP per capita. Although the influence coefficient is relatively weak, it is positive, and it is significant at the level of $1 \%$. Comparing our research results to Crozet and Koenig's [5] results, the influence coefficient is similar to that of European countries (0.025-0.076), which shows that regional inequality has a positive influence on regional economic growth up to a certain threshold. This further confirms our previous assertion. However, the thresholds are difficult to calculate because we cannot be sure of the degree of regional inequality that was conducive to regional economic growth.

For a long time, research on regional economic growth inequality has tended to focus on measuring regional inequality, and there has been a lack of research on the influence of regional inequality on economic growth. Most scholars believe that regional inequality is harmful to economic growth. It turns out, however, that there is no monotonic, linear relationship between regional inequality and economic growth; rather, there is a complex interactive coupling relationship between the two. The role regional economic inequality plays in affecting economic growth of individual economic entities still requires empirical analysis targeting different observed units and different time samples. Nevertheless, there remains today a lack of relevant discussion on the specific threshold at which the influence of regional economic growth inequality turns from positive to negative. From the perspective of analyzing externalities, this transition is more like the transition from a positive externality to a negative externality. From the perspective of the regional economic inequality versus economic growth trade-off, this method undoubtedly provides a quantitative expression approach. Judging the influence of economic inequality on economic growth by whether the influence coefficient is positive or negative can not only serve as an early warning of the extent of regional economic inequality, but it can also test the influence of externalities on economic growth.

\subsection{Spillover Effects of Prefecture-Level Economic Growth}

Table 3 shows the results of calculations on the spatial spillover effects of prefecture-level economic growth in China. The analysis results showed that the influence of market potential on GDP per capita growth, that is, the direct spillover effect between regions, was significantly positive in all the estimation models. This result was consistent with the theoretical analysis. Moreover, the elastic value of the variable of market potential far exceeded other factors, whereas the influence coefficient was consistently between 0.91 and 0.94 . Looking at several factors of production, the workforce participation rate was most influential, with an influence coefficient of 0.19-0.21. The influence of human capital was slightly weaker, with an influence coefficient of 0.08-0.1. Corresponding per capita fixed-asset investment was the weakest of the major factors, with an influence coefficient of 0.004-0.006. All of the above factors were significant at the level of $1 \%$. The variables of the distance from each prefecture to the nearest seaport and the distance from each prefecture to the nearest provincial capital had a negative influence in every model. This suggests that greater distance from a seaport increases the cost of entering an overseas market and reduces accessibility to corresponding foreign products, investment, and services, which has a negative influence on regional economic growth. This result was in line with the actual economic development of China, especially in the early stage of reform and opening-up. The coastal regions and cities located around big cities with a favorable location captured economic development priorities and opportunities. 
Table 3. Regression results of prefecture-level economic growth spillover effects (Source: modified by the authors).

\begin{tabular}{|c|c|c|c|c|c|c|c|}
\hline & \multirow[b]{2}{*}{$\begin{array}{l}\text { Pooled } \\
\text { OLS }\end{array}$} & \multicolumn{3}{|c|}{ SAR } & \multicolumn{3}{|c|}{ SEM } \\
\hline & & $\begin{array}{l}\text { Spatial } \\
\text { Fixed }\end{array}$ & $\begin{array}{l}\text { Time-Period } \\
\text { Fixed }\end{array}$ & $\begin{array}{c}\text { Spatial and } \\
\text { Time-Period } \\
\text { Fixed }\end{array}$ & $\begin{array}{l}\text { Spatial } \\
\text { Fixed }\end{array}$ & $\begin{array}{l}\text { Time-Period } \\
\text { Fixed }\end{array}$ & $\begin{array}{c}\text { Spatial and } \\
\text { Time-Period } \\
\text { Fixed }\end{array}$ \\
\hline Constant term & $\begin{array}{c}0.0108^{* * *} \\
(3.8626)\end{array}$ & & & & & & \\
\hline $\ln \left(\mathrm{MP}_{\mathrm{r}, \mathrm{t}} / \mathrm{MP}_{\mathrm{r}, \mathrm{t}-1}\right)$ & $\begin{array}{l}0.9324^{* * *} \\
(606.4544)\end{array}$ & $\begin{array}{c}0.9134^{* * *} \\
(1364.4164)\end{array}$ & $\begin{array}{c}0.9110^{* * *} \\
(772.0901)\end{array}$ & $\begin{array}{l}0.9143 * * * \\
(894.0954)\end{array}$ & $\begin{array}{l}0.9243 * * * \\
(570.8259)\end{array}$ & $\begin{array}{l}0.9298 * * * \\
(594.1351)\end{array}$ & $\begin{array}{l}0.9325 * * * \\
(590.1723)\end{array}$ \\
\hline $\ln \left(\mathrm{L}_{\mathrm{r}, \mathrm{t}} / \mathrm{L}_{\mathrm{r}, \mathrm{t}-1}\right)$ & $\begin{array}{l}0.1935^{* * *} \\
(31.3040)\end{array}$ & $\begin{array}{l}0.1901^{* * *} \\
(31.7464)\end{array}$ & $\begin{array}{l}0.1908^{* * *} \\
(31.5050)\end{array}$ & $\begin{array}{l}0.1930^{* * *} \\
(32.3805)\end{array}$ & $\begin{array}{l}0.1929^{* * *} \\
(31.2697)\end{array}$ & $\begin{array}{l}0.1997^{* * *} \\
(32.4795)\end{array}$ & $\begin{array}{l}0.2017^{* * *} \\
(33.3279)\end{array}$ \\
\hline $\ln \left(K_{\mathrm{r}, \mathrm{t}} / \mathrm{K}_{\mathrm{r}, \mathrm{t}-1}\right)$ & $\begin{array}{l}0.0047^{* * *} \\
(12.2319)\end{array}$ & $\begin{array}{l}0.0040^{* * *} \\
(10.8273)\end{array}$ & $\begin{array}{l}0.0041^{* * *} \\
(11.4351)\end{array}$ & $\begin{array}{l}0.0038^{* * *} \\
(10.6084)\end{array}$ & $\begin{array}{l}0.0055^{* * *} \\
(13.0024)\end{array}$ & $\begin{array}{l}0.0045^{* * *} \\
(11.2657)\end{array}$ & $\begin{array}{l}0.0040^{* * *} \\
(10.3588)\end{array}$ \\
\hline $\ln \left(\mathrm{H}_{\mathrm{r}, \mathrm{t}} / \mathrm{H}_{\mathrm{r}, \mathrm{t}-1}\right)$ & $\begin{array}{l}0.0930^{* * *} \\
(36.3545) \\
\end{array}$ & $\begin{array}{l}0.0984^{* * *} \\
(38.7937) \\
\end{array}$ & $\begin{array}{l}0.0888^{* * *} \\
(35.8573) \\
\end{array}$ & $\begin{array}{l}0.0949^{* * *} \\
(38.1393) \\
\end{array}$ & $\begin{array}{l}0.0960^{* * *} \\
(37.1312) \\
\end{array}$ & $\begin{array}{l}0.0911^{* * * *} \\
(35.7903) \\
\end{array}$ & $\begin{array}{l}0.0962 * * * \\
(37.7130)\end{array}$ \\
\hline lndpr & $\begin{array}{l}-0.0008^{*} \\
(-1.6993)\end{array}$ & $\begin{array}{l}-0.0003 * \\
(-0.8765)\end{array}$ & $\begin{array}{l}-0.0008^{*} \\
(-1.6441)\end{array}$ & $\begin{array}{c}-0.3088^{* * *} \\
(-2.7862)\end{array}$ & $\begin{array}{l}-0.0009^{*} \\
(-1.7066)\end{array}$ & $\begin{array}{c}-0.0008 \\
(-1.6203)\end{array}$ & $\begin{array}{l}-0.2758^{* * *} \\
(-14.5274)\end{array}$ \\
\hline lndcr & $\begin{array}{c}-0.0013^{* *} \\
(-2.0042)\end{array}$ & $\begin{array}{l}-0.0002 * \\
(-0.5642)\end{array}$ & $\begin{array}{c}-0.0013^{* *} \\
(-1.9705)\end{array}$ & $\begin{array}{c}-0.7919^{* * *} \\
(-3.2456)\end{array}$ & $\begin{array}{c}-0.0009 \\
(-1.2916) \\
\end{array}$ & $\begin{array}{c}-0.0009 \\
(-1.3420) \\
\end{array}$ & $\begin{array}{c}-0.7256^{* * *} \\
(-2.7686) \\
\end{array}$ \\
\hline$\delta$ & & $\begin{array}{l}0.0530 * * * \\
(13.0567)\end{array}$ & $\begin{array}{l}0.0580^{* * *} \\
(11.5960)\end{array}$ & $\begin{array}{c}0.0550 \\
(11.6996)\end{array}$ & & & \\
\hline$\rho$ & & & & & $\begin{array}{c}0.1600 * * * \\
(23.1232)\end{array}$ & $\begin{array}{l}0.1480^{* * *} \\
(16.8652)\end{array}$ & $\begin{array}{l}0.1340^{* * *} \\
(14.5274)\end{array}$ \\
\hline Adjusted $\mathrm{R}^{2}$ & 0.9267 & 0.9259 & 0.9284 & 0.9257 & 0.9277 & 0.9272 & 0.9301 \\
\hline$\sigma^{2}$ & 0.0060 & 0.0056 & 0.0059 & 0.0056 & 0.0059 & 0.0060 & 0.0057 \\
\hline LM spatial lag & $872.94^{* * *}$ & $875.23 * * *$ & $876.35^{* * *}$ & $879.09 * * *$ & $865.35^{* * *}$ & $862.13^{* * *}$ & $879.33^{* * *}$ \\
\hline LM spatial error & $962.91 * * *$ & $978.45^{* * *}$ & $978.24^{* * *}$ & $976.25^{* * *}$ & $975.34^{* * *}$ & $1000.35^{* * *}$ & $1012.13^{* * *}$ \\
\hline Robust LM spatial lag & $298.47^{* * *}$ & $299.24^{* * *}$ & $298.30^{* * *}$ & $294.21^{* * *}$ & $291.24^{* * *}$ & $305.32 * * *$ & $309.46^{* * *}$ \\
\hline Robust LM spatial error & $388.44^{* * *}$ & $389.25^{* * *}$ & $386.36^{* * *}$ & $382.35^{* * *}$ & $451.54^{* * *}$ & $439.46^{* * *}$ & $469.01^{* * *}$ \\
\hline Log-likelihood & 33,781 & 34,801 & 34,033 & 34,667 & 33,926 & 33,824 & 34,449 \\
\hline Observation & 330 & 330 & 330 & 330 & 330 & 330 & 330 \\
\hline
\end{tabular}

Note: $t$-test values are provided in parentheses; ${ }^{* * *}$ indicates significant at the level of $1 \%$; ${ }^{* *}$ indicates significant at the level of $5 \%{ }^{*}$ indicates significant at the level of $10 \%$.

The fixed effect model is still the choice of model estimation method. Comparing the parameters of the SAR, SEM, and OLS models, the SEM spatial and time-period fixed model is the most appropriate model. Looking at adjusted $\mathrm{R}^{2}$, LM test, robust LM test, and log-likelihood, the SEM model is better than the traditional OLS model, which further shows the necessity and correctness of considering spatial effects. Looking at the specific results of the SEM spatial and time-period fixed model, the influence coefficient of market potential was as high as 0.9325 , which indicated that direct spatial spillover effects, as represented by market potential, had a strong positive influence on the economic growth of prefectures in China in the period of 1992-2013. If other factors were controlled, market potential increased by $0.93 \%$ and it could promote prefecture-level GDP per capita growth by $1 \%$. This is consistent with the theory of new economic geography. In addition, using the SEM spatial and time-period fixed model, it was shown that the spatial autocorrelation $\rho$ significance was not zero, and that it was significant at the level of $1 \%$, with a specific coefficient of 0.1340 . This result suggested that the economic growth of prefectures in China was also closely related to the random impact of the surrounding prefectural economic growth. This shows that in addition to the influencing factors that we have specified, there are other factors that play a proliferating or spillover role in the economic growth of surrounding prefectures. Some scholars consider them "indirect spatial spillover effects". Combining direct and indirect spillover effects, it was found that spillover effects played an important role in the economic growth of China's prefectures between 1992 and 2013.

The SEM spatial and time-period fixed model results showed that other factors of production also had different influences on the economic growth of prefectures. The labor participation rate 
had a significant positive influence on the economic growth of prefectures. Indeed, for every 1 percentage point increase in the labor participation rate, GDP per capita of prefectures increased by 0.2017 percentage points. Human capital also showed a positive influence, although its influence coefficient was significantly weaker than the labor participation rate. This shows that China's prefecture-level economic growth was more dependent on the labor force and the demographic dividend in the period of 1992-2013. The influence of human capital was not as high as expected, however. In terms of the workforce, it means that China's prefecture-level economic growth is still in its developmental stage. The influence of per capita fixed-asset investment on prefecture economic growth was also slightly different than expected. For every $10 \%$ increase in per capita fixed-asset investment, GDP per capita increased $0.04 \%$. Both distance to the nearest seaport and distance to the nearest provincial capital displayed a significant negative influence. This illustrates that cost and locational factors to enter foreign markets have an important influence on regional economic growth.

\section{Discussion and Policy Implications}

Research on drivers of rapid regional economic development in China has long been a core area of interest for Chinese and international scholars. However, in addition to the basic factors of production recognized by traditional economic growth theory, externalities of spatial agglomeration and spillover effects have gradually been recognized by new economic geography and related disciplines in recent years. To understand the economic growth agglomeration versus spatial inequality trade-off as well as spatial spillover effects at the prefecture level in China, this study conducted a quantitative analysis of a sample of Chinese prefectures based on the theory of new economic geography and taking market potential as the core variable.

This paper utilized the classic wage model of economic geography as the theoretical starting point to analyze the mechanisms of China's prefecture-level economic growth agglomeration via the interactions and relationship between market potential and regional inequality. A quantitative analysis of 330 prefectures between 1992 and 2013 revealed, first of all, that market potential had a significant positive influence on prefecture-level economic growth, economic growth of surrounding regions had a strong spillover effect on the economic growth of prefectures, and economic agglomeration was an objective result of this spatial spillover. It also revealed that economic agglomeration led to regional inequality, but greater regional inequality promoted economic growth if it was within a reasonable range. In our opinion, one of the reasons for this logic framework is that the economic growth agglomeration of prefectures can help boost the economic efficiency. Additionally, economic efficiency is also one of the necessary prerequisites for economic growth agglomeration. Therefore, economic growth agglomeration located in specific and small fraction regions may result in regional inequality. This regional inequality can be considered as a "by-product" of agglomeration development.

Many policy implications can be derived from these findings. First, an important revelation is that it is necessary to prioritize the development of urban agglomerations and megalopolises with high levels of economic agglomeration and high-density urbanized areas when formulating regional policies, so as to use economically efficient regional development to drive the development of surrounding areas using the spatial diffusion effect. It would also be wise to control regional inequality within reasonable limits using early warning analysis and setting rational thresholds, as well as to develop response strategies based on certain thresholds. Controlling regional inequality has become a global problem. For example, goal 10 of the Sustainable Development Goals (SDGs) aims to reduce inequality within and among countries. To reduce regional inequality, policies should be universal in principle, giving attention to the needs of disadvantaged and marginalized prefectures. Finally, innovations in technology can help to reduce the cost of transferring money for the least developed prefectures. Therefore, offering preferential policies of technology application to these prefectures is a convenient way to reduce regional disparity.

Second, this paper combined classical economic growth theory, new economic growth theory, and new economic geography theory to explore the spatial spillover effects of prefecture-level economic 
growth in China (i.e., the extent to which a prefecture's economic growth is influenced by the economic growth of surrounding prefectures) using the explanatory variables of market potential and basic factors of production. Our econometric analysis shows that China's prefecture-level economic growth has not yet rid itself of the influence of factors of production as proposed by traditional economic growth theory, and that direct spillover effects, such as market potential, have the most significant and strongest positive influence on prefecture-level economic growth, as it has a higher influence coefficient than all other factors. We also found that in addition to the influence of direct spillover effects, economic growth of prefectures is inseparable from the random impacts of surrounding prefectures, and they are also affected by indirect spatial spillover effects. From the perspective of regional policy, the existence of significant spatial spillover implies that local government decision-making affects not only their own prefectures but also neighboring ones, thereby requiring the central government to pay special attention to coordination across local administrative units, such as prefectures. This has also revealed to us the need to gradually eliminate barriers of local protectionism in the course of economic growth to improve market accessibility, strengthen regional economic links and interactions, and improve hardware such as interregional road and other regional infrastructures. It is also necessary to improve the regional soft environment to improve the efficiency of economic links and provide platforms and spaces for spillovers. Improving the prefecture-level business environment is one of the important aspects of regional soft environment. For developed prefectures, it is necessary to accelerate the active industry transfer to undeveloped prefectures. On the one hand, developed prefectures need to attain a higher level of industrial evolution and eliminate backward industries which mismatched the industrial development direction of these prefectures. On the other hand, these transferred industries for undeveloped prefectures are still relatively advanced. The undeveloped prefectures that have accepted the industrial transfers need to choose appropriate industries matching their industrial development condition and to implement a series of preferential policies to accelerate industrial transfer.

Third, it was an important task of this study to examine how to boost drivers of China's prefecture-level economic growth. Using econometric analysis, it was found that the labor participation rate was second only to spatial spillover effects as an influencing factor, and the roles of human capital and fixed-asset investment were relatively weak. On the whole, China's prefecture-level economic growth is still benefitting from the workforce dividend caused by its demographic dividend. Moreover, dependence on human capital and physical capital was found to be relatively weak, which meant that prefecture-level economic growth had not entered the stage of high-quality development. As China's population ages in the foreseeable future, China's workforce dividend will diminish to nothing. That being the case, gradually improving the overall competency and skills of the workforce so as to maximize human capital will be key to prefectures improving the quality of their economic growth. In addition, improving the level and intensity of prefecture-level investment is an important means of promoting economic growth. In policy, with the more intense market competition, greater attention should be paid to persistently enhancing the education level of workers by implementing an education priority policy, establishing a modern education system, improving education quality, and promoting educational equity. Moreover, if the central or local governments invest more in education, this will help to reduce regional inequality.

In summary, rationally utilizing the benefits of regional economic agglomeration and spatial spillover effects, boosting drivers of prefecture-level economic growth, and striving to transform the development pattern of prefecture-level economic growth will be key to economic growth in the future.

\section{Conclusions}

The main goals of the current study were to explore the economic growth agglomeration versus spatial inequality trade-off, investigate direct and indirect spatial spillover effects as well as the drivers of economic growth at the prefecture level in China from 1992 to 2013. 
Our analysis revealed the following main conclusions. First, the results showed that economic agglomeration, represented by market potential, had a significant influence on economic growth at the prefecture level in China. Meanwhile, economic agglomeration aggravated regional economic inequality, but economic inequality within a controllable range was found to have a positive influence on economic growth. Thus, there is a trade-off between economic growth and economic agglomeration.

Second, there was significantly positive spatial spillover across Chinese prefectures, and the spatial spillover effect between prefectures played an important role in the economic development of China. We furthermore found that the direct spillover effects, such as market potential, had the most significant and strongest positive influence on prefecture-level economic growth. We also found that in addition to the influence of direct spillover effects, the economic growth of prefectures was inseparable from the random impacts of surrounding prefectures, and that they were also affected by indirect spatial spillover effects.

Third, the econometric results showed that prefecture-level economic growth in China had not entered the stage of high-quality development from 1992 to 2013, and it has not yet rid itself of the influence of factors of production. The labor participation rate had a significant positive influence on the economic growth of prefectures. However, the effect of human capital on economic growth was significantly weaker than the labor participation rate. This suggests that China's prefecture-level economic growth was more dependent on the labor force and the demographic dividend in the period of 1992-2013. Contrary to expectations, the influence of per capita fixed-asset investment on prefecture economic growth was slightly weak. The cost and locational factors to enter foreign markets also had an important influence on regional economic growth.

Finally, important policy implications on economic growth of China at the prefecture level were proposed.

Author Contributions: This study is a joint work of the two authors. F.L. and G.L. contributed to the design of the research; F.L. and G.L. analyzed the data; and F.L. and G.L. wrote the manuscript.

Funding: This research was supported by the Strategic Priority Research Program of the Chinese Academy of Sciences, the Pan-Third Pole Environment Study for a Green Silk Road (Pan-TPE) (No. XDA20040400), and the National Natural Science Foundation of China (Nos. 71433008 and 41501175).

Acknowledgments: The authors would like to thank the anonymous reviewers and editors for commenting on this paper.

Conflicts of Interest: The authors declare no conflict of interest.

\section{References}

1. World Bank. World Development Indicators 2017; The World Bank: Washington, DC, USA, 2018.

2. Wei, Y.D.; Yu, D.L.; Chen, X.J. Scale, Agglomeration, and Regional Inequality in Provincial China. Tijdschr. Voor Econ. En Soc. Geogr. 2011, 102, 406-425. [CrossRef]

3. Hirschman, A.O. The Strategy of Economic Development; Yale University Press: Newhaven, CT, USA, 1958.

4. Myrdal, G. Economic Theory and Under-Developed Regions; Duckworth: London, UK, 1957.

5. Crozet, M.; Koenigy, P. The Cohesion vs. Growth Tradeoff: Evidence from EU Regions (1980-2000); Working Paper; ERSA: Louvain-la-Neuve, Belgium, 2005.

6. Fan, C.C.; Scott, A.J. Industrial agglomeration and development: A survey of spatial economic issues in East Asia and a statistical analysis of Chinese regions. Econ. Geogr. 2003, 79, 295-319. [CrossRef]

7. He, C.F.; Wei, Y.H.D.; Pan, F.H. Geographical concentration of manufacturing industries in China: The importance of spatial and industrial scales. Eurasian Geogr. Econ. 2007, 48, 603-625. [CrossRef]

8. Pan, W.Q. Regional linkage and the spatial spillover effects on regional economic growth in China. Econ. Res. J. 2012, 1, 54-65. (In Chinese)

9. Ying, L.G. Understanding China's recent growth experience: A spatial econometric perspective. Ann. Reg. Sci. 2003, 37, 613-628. [CrossRef]

10. Brun, J.F.; Combes, J.L.; Renard, M.F. Are there spillover effects between coastal and noncoastal regions in China? China Econ. Rev. 2002, 13, 161-169. [CrossRef] 
11. Groenewold, N.; Guoping, L.; Anping, C. Regional output spillovers in China: Estimates from a VAR model. Pap. Reg. Sci. 2007, 86, 101-122. [CrossRef]

12. Groenewold, N.; Lee, G.P.; Chen, A.P. Inter-regional spillovers in China: The importance of common shocks and the definition of the regions. China Econ. Rev. 2008, 19, 32-52. [CrossRef]

13. Groenewold, N.; Chen, A.P.; Lee, G.P. Inter-regional Spillovers of Policy Shocks in China. Reg. Stud. 2010, 44, 87-101. [CrossRef]

14. Tian, L.; Wang, H.H.; Chen, Y.J. Spatial externalities in China regional economic growth. China Econ. Rev. 2010, 20, S20-S31. [CrossRef]

15. LeSage, J.P. Spatial econometrics: Statistical foundations and applications to regional convergence, by Giuseppe Arbia. J. Reg. Sci. 2007, 47, 646-648. [CrossRef]

16. Anselin, L. Spatial Economy: Methods and Models; Kluwer Academic Publisher: Dordrecht, The Netherlands, 1988.

17. Cliff, A.; Ord, J.K. Testing for spatial autocorrelation among regression residuals. Geogr. Anal. 1972, 4, 267-284. [CrossRef]

18. Fujita, M.; Krugman, P.; Venables, A.J. The Spatial Economy: Cities, Regions, and International Trade; MIT Press: Cambridge, MA, USA, 2001.

19. Shankar, R.; Shah, A. Bridging the economic divide within countries: A scorecard on the performance of regional policies in reducing regional income disparities. World Dev. 2003, 31, 1421-1441. [CrossRef]

20. Lessmann, C.; Seidel, A. Regional inequality, convergence, and its determinants-A view from outer space. Eur. Econ. Rev. 2017, 92, 110-132. [CrossRef]

(C) 2018 by the authors. Licensee MDPI, Basel, Switzerland. This article is an open access article distributed under the terms and conditions of the Creative Commons Attribution (CC BY) license (http:/ / creativecommons.org/licenses/by/4.0/). 